\title{
Increasing the Capacity of Existing Bridges by Using Unbonded Prestressing Technology: A Case Study
}

\author{
Antonino Recupero, ${ }^{1}$ Nino Spinella, ${ }^{1}$ Piero Colajanni, ${ }^{2}$ and Cosimo D. Scilipoti ${ }^{3}$ \\ ${ }^{1}$ Dipartimento di Ingegneria Civile, Informatica, Edile, Ambientale e Matematica Applicata, Università di Messina, \\ Contrada di Dio, Villaggio S. Agata, 98166 Messina, Italy \\ ${ }^{2}$ Dipartimento di Ingegneria Civile, Ambientale, Aerospaziale e dei Materiali (DICAM), Università di Palermo, \\ Viale delle Scienze, 90128 Palermo, Italy \\ ${ }^{3}$ Ré Engineering S. R. L., Via S. Francesco di Paola 264, Barcellona P.G., 98051 Messina, Italy
}

Correspondence should be addressed to Nino Spinella; nspinella@unime.it

Received 6 February 2014; Revised 20 June 2014; Accepted 29 June 2014; Published 23 July 2014

Academic Editor: Andreas Kappos

Copyright (C) 2014 Antonino Recupero et al. This is an open access article distributed under the Creative Commons Attribution License, which permits unrestricted use, distribution, and reproduction in any medium, provided the original work is properly cited.

\begin{abstract}
External posttensioning or unbonded prestressing was found to be a powerful tool for retrofitting and for increasing the life extension of existing structures. Since the 1950s, this technique of reinforcement was applied with success to bridge structures in many countries, and was found to provide an efficient and economic solution for a wide range of bridge types and conditions. Unbonded prestressing is defined as a system in which the post-tensioning tendons or bars are located outside the concrete crosssection and the prestressing forces are transmitted to the girder through the end anchorages, deviators, or saddles. In response to the demand for a faster and more efficient transportation system, there was a steady increase in the weight and volume of traffic throughout the world. Besides increases in legal vehicle loads, the overloading of vehicles is a common problem and it must also be considered when designing or assessing bridges. As a result, many bridges are now required to carry loads significantly greater than their original design loads; and their deck results still deteriorated by cracking of concrete, corrosion of rebars, snapping of tendons, and so forth. In the following, a case study about a railway bridge retrofitted by external posttensioning technique will be illustrated.
\end{abstract}

\section{Introduction}

In Europe, the motorway and railway networks were built about 30 to 40 years ago [1]; they have a large number of prestressed concrete bridges and viaducts. Many reinforced concrete bridges in highway systems are deteriorated and/or distressed to such a degree that structural strengthening of the bridge or reducing the allowable truck loading on the bridge by load posting is necessary to extend the service life of the bridge [2]. Besides, in motorway networks, over the last few decades, there was a rapid increase in traffic volume and weight of heavy vehicles and contemporarily there was a rapid increase in transit speed on railway networks. Many bridges, which were built with now obsolete design standards, are not able to carry on the recent traffic requirements and they require either weight or speed restriction, the strengthening, or, even, the total replacement [2].

Various methods for the rehabilitation of bridges are currently available including the addition of structural reinforcement components as steel rebar or reinforced concrete (RC) jackets and bonded steel plates.

Two methods are currently proving to be very useful in increasing the cross-section capacity of the bridge beam: the strengthening by fibres reinforced polymer (FRP) or fiber reinforced cementitious mortar (FRCM) [3-10] and the reinforcement with external tendons.

The effect of FRP or FRCM sheets and external prestressing tendons on the strength of RC beams has largely 
been investigated [11] with success. However, in some cases external bonded FRP or FRCM could not be sufficient to strengthen the main girder of bridge.

In addition, their use is characterized by elevated costs, poor resistance to fire, and difficulties in maintenance, especially for bridge decks.

External prestressing tendons bear the applied load, thus improving the load-carrying capacity and effectively extending the service life of the structure [12]. The use of external unbonded reinforcement offers the potential of providing a more cost effective and less disruptive solution to the problem of strengthening RC beams.

The external tendons are easily inspected and poor workmanship or corrosion of external reinforcement can be easily checked and monitored. They are also compatible with principles of conservation which require that a structure be returned to its original condition after any interventions.

Several owners also require that operations of bridge retrofitting occur with minimal disruption to traffic flow. For this reason the technique of externally posttensioning is growing in popularity thanks to the speed of installation and the minimal disturbance to traffic flow.

The goal of this work is to describe the method of external posttensioning as a means of retrofitting bridges which have been found to be understrength. The paper shows the principles of external posttensioning and presents, as a case study, the retrofitting of a single span bridge in Novara (North of Italy). During the construction of the railway line TurinNovara the Consortium CAV.TO.MI. required to use the road bridge, namely, Terdoppio, for the transit of the railway trains to place the equipment of the railway line. Therefore, the traffic loads would be increased and reinforcement was necessary. In particular, the external tendons system was chosen to be used. In this case, to provide the space for the anchoring of the external cables, a demolition of existing grate walls was needed. But the retrofitting method is applicable for multispan bridge also, depending on boundary conditions. For example, Bertagnoli et al. [13] have illustrated a similar retrofitting application on a multispan bridge, realizing some housing pockets for the external cables on the side web of the lateral beams. However, different solutions can be pursued as function of costs and feasibility of the intervention, which should be assessed on a case-by-case basis.

Moreover, the prestressed concrete (PC) beam of Terdoppio bridge was numerically analyzed at the ultimate limit state (ULS) to compare the load capacity of reinforced beam evaluated by a handy sectional method with a nonlinear finite element analysis (NLFEA). At this aim, the VecTor2 finite element software, which is based on the Modified Compression Field Theory (MCFT) [14], was used.

The MCFT is a smeared rotating crack model. The key assumption the MFCT uses to simplify is that the principal strain directions coincide with the principal stress directions. This assumption has recently been removed by Vecchio [15] which has introduced the disturbed stress field model (DSFM). The DSFM explicitly incorporates rigid slipping along crack surfaces into the compatibility relations for the element, allowing for a divergence of the angles of inclination

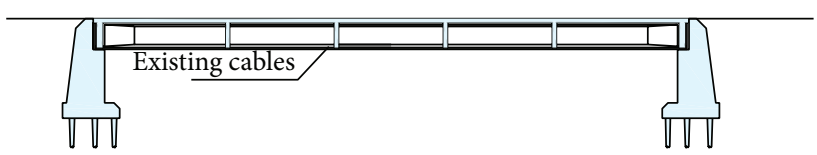

(a)

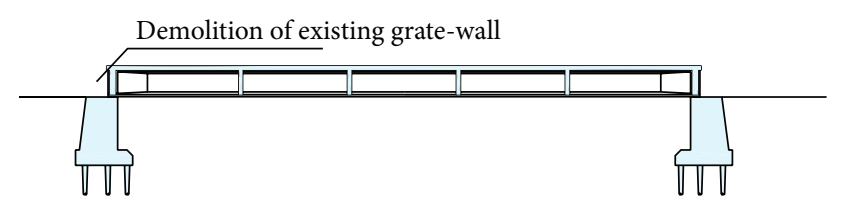

(b)

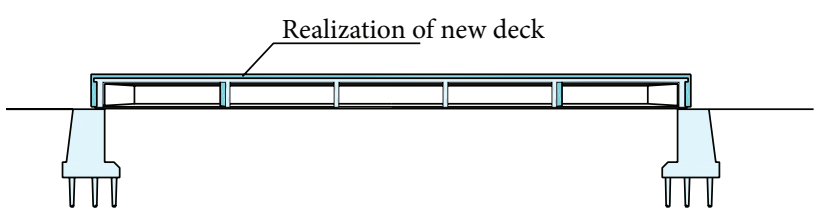

(c)

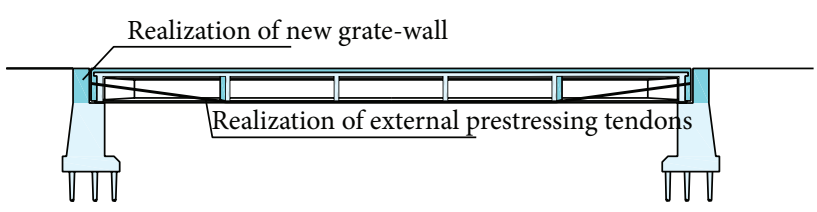

(d)

FIGURE 1: Longitudinal section of (a) existing bridge, (b) demolition of gravel-grate walls and elimination of road superstructure, (c) realization of a new deck, and (d) realization of new gravel-grate walls and a system of external prestressing.

of average principal stress and apparent average principal strain in the concrete.

In addition, MCFT and DSFM have been recently extended to the case of FRC elements [16-18], proving their general capacity to reproduce the response of structural members with different mechanical and load conditions.

\section{A Case Study: The Terdoppio Bridge}

2.1. Need of Rehabilitation for the Terdoppio Bridge. In 2006, during the works for the construction of the railway line Turin-Novara, the Consortium CAV.TO.MI. (i.e., the general contractor) needed to use the Terdoppio road bridge for the transit of the railway cars. This single span bridge (Figure 1(a)) was provisionally used as bypass of the existing principal line that was under replacement.

The road bridge on the river Terdoppio was built in the early 70s and it is constituted by a deck of six prestressed and prefabricated beams and six diaphragms which were casted in situ. Preliminary analyses pointed out that the existing structure was not fit to allow the transit of the carriage railway and it was therefore necessary to adjust or replace it.

The two solutions were also estimated from the economic point of view. The owner chose to make the reinforcement and the adjustment of the bridge. The rehabilitation was projected and then was developed in the way less intrusive as possible. The minimum interference on the existing structure, 


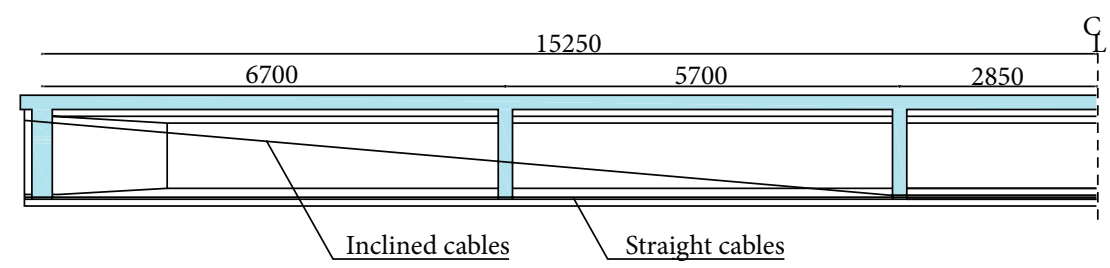

(a)

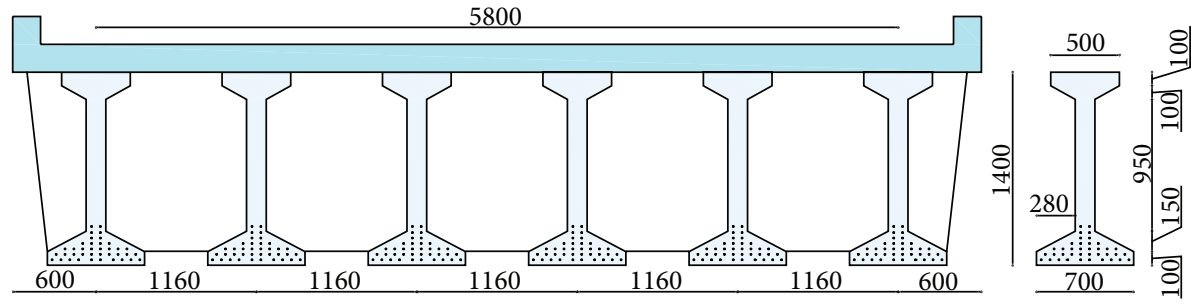

(b)

FIgURE 2: (a) Longitudinal and (b) transversal scheme of existing bridge.

as imposed by the company, was planned by the following phases:

(i) demolition of gravel-grate walls and removal of road superstructure and concrete milling of the existing surface deck: both steps have accounted for around the $12 \%$ of total intervention costs (Figure 1(b));

(ii) realization of a new deck of $250 \mathrm{~mm}$ thickness on the existing deck: the new deck is able to bear the new railway local loads; it is linked to the original structure by steel connectors (Figure 1(c));

(iii) realization of a system of external prestressing with 10 cables 8/0.6" strands, anchored close to the support diaphragms and with metallic deviator on intermediate diaphragms: there is realization of new gravelgrate walls (Figure $1(\mathrm{~d})$ ).

The phase of planning of adjustment was preceded by a wide campaign of nondestructive investigations that allowed the best calibration of the subsequent choices. In the planning of the system of rehabilitation, the combined effect of existing bonded prestressing and new unbonded external prestressing was taken into account.

2.2. Geometrical and Mechanical Investigation of Terdoppio Bridge. The Terdoppio bridge is a classical typology of "Grillage Bridge." The single span of bridge is $30.5 \mathrm{~m}$ (Figure 2). The beams have a cross-section with a height equal to $1.4 \mathrm{~m}$ and they were prestressed with the pretension method with 38 strands $\left(A_{p}=93 \mathrm{~mm}^{2}\right.$ for each). The tensile strength at ULS is $f_{t}=1750 \mathrm{MPa}$. The strands present a polygonal layout with a horizontal central part large of $6 \mathrm{~m}$.

The original design was recovered for accurate calibration, obtaining also information about the load tests performed on the structure during construction. For integrating these data, it was chosen to program a campaign of nondestructive in situ tests, and particularly some core borings on the existing deck were also integrated by SONinc-REBound (SONREB) tests on concrete beams and diaphragms.

Relationships proposed in literature about SONREB offered an indirect estimation of concrete strength $\left(f_{\mathrm{cm}}\right)$ in different parts of bridge structure.

For the concrete of existing beams, following the series of destructive and nondestructive tests, it was reasonable to assume a class C35/45, typical of the prefabrication industry of that period. In existing deck slab, by analyzing the results of nondestructive and destructive tests on specimens, it was reasonable to assume for the concrete a class C20/25.

The check phase, based on data provided by the preliminary tests, emphasized that the existing structure was not suitable to allow the transit of the railway coaches as required by the national code specifications.

In fact, the authorities' specifications require the passage of the following:

(1) a testing train for high-speed bridges that were in construction: it is composed of 24 axles each of $210 \mathrm{kN}$ capacity for a total of $5040 \mathrm{kN}$; this train could easily be packed in the ballast field and it had to cross the Terdoppio bridge for reaching the railway line in construction;

(2) an equivalent train to the LM71 reduced to the $83 \%$ as required by the ITALFERR Manual Code [19] for railway bridges classified as Category B;

(3) a train of coaches that bear the ballast (Figure 3), with a total load for each coach equal to $800 \mathrm{kN}$ on 4 axles.

Therefore, the bridge needed the rehabilitation or the replacement.

2.3. Scheme of Rehabilitation Proposed. Different hypotheses of adjustment have attentively been valued:

(1) assemblage of a metallic structure of inclined-leg frame typology under the existing structure; 


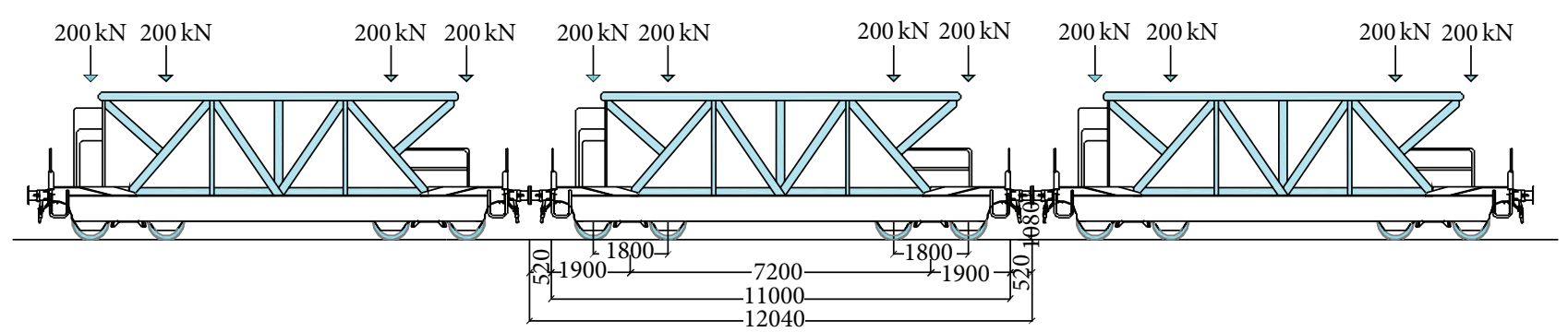

FIgURE 3: Multiple coaches for ballast train.
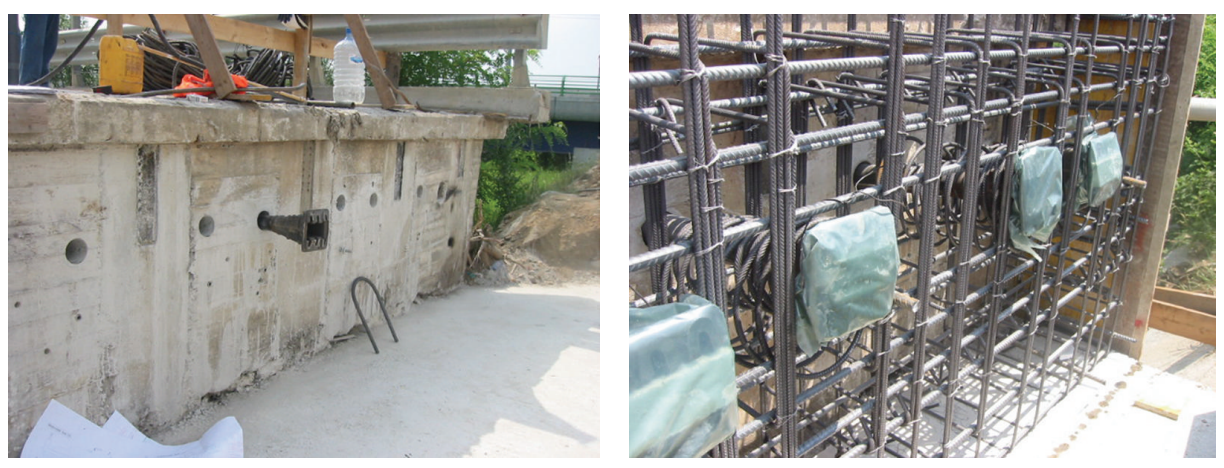

FIGURE 4: Anchor heads and antispalling reinforcement.

(2) reinforcement of principal beams with FRP plates on the bottom face of the beams [20];

(3) reinforcement of principal beams with a system of unbonded prestressing, external to cross-section of beams.

After a wealthy debate with the contractor and Italian railway authorities, the third proposal for economic motivation was chosen. Moreover, for avoiding excessive costs, only a partial rehabilitation of the bridge was selected, by allowing totally the transit of the train equivalent to the LM71 to reduce to the $83 \%$ and of the train that bears the ballast (Figure 3 ) and the load of a testing train (for High-Speed bridges) with reduction to $60 \%$. The total recharge up to $100 \%$ of the testing train would have happened after the transit on the bridge.

It was decided, therefore, to apply a system of external prestressing with 10 external cables of 8 strands $0.6^{\prime \prime}$ which, departing from the diaphragms of extremity already reconstructed for lodging the prestress anchorage, were deviated by the first intermediary diaphragm (those posed at 3/4 of span). It was chosen to have steel deviator arrangements on diaphragms.

For rationalizing the operations of adjustment, the following executive phases were selected:

(1) removal of road superstructure and concrete milling of the existing surface slab;

(2) assemblage of the connectors for the integrative new slab;

(3) positioning of the bars of reinforcement and the casting of integrative slab;
(4) demolition of top part of abutment and setup of the plan of work on altitude of existing bearings;

(5) positioning of the anchor heads and the antispalling reinforcement; the casting of integrative diaphragm (Figure 4);

(6) installation of the metallic saddles of deviation under $3 / 4$ diaphragms, using rebar and epoxy resin to connect the two components (Figures 5 and 6);

(7) lodging of the integrative external cables and their prestressing up to nominal force;

(8) casting of new top part of abutments and reconstruction of their backfills;

(9) positioning of the joints between deck and abutments;

(10) placing of ballast and rails;

(11) final testing with the trains used in design phases (Figure 3).

For each phase of construction the corresponding check calculations were performed. The new slab, with a thickness of $250 \mathrm{~mm}$, was necessary to bear greater local loads than previous. It was casted with concrete of class C35/45. The new slab increased the total height of transversal sections of beams with a notable improvement in terms of stiffness and load capacity.

\section{Numerical Model}

3.1. Numerical Analyses of Strengthened Beams. The proposed rehabilitation scheme for the Terdoppio bridge was investigated with deep attention to evaluate the new bearing load 


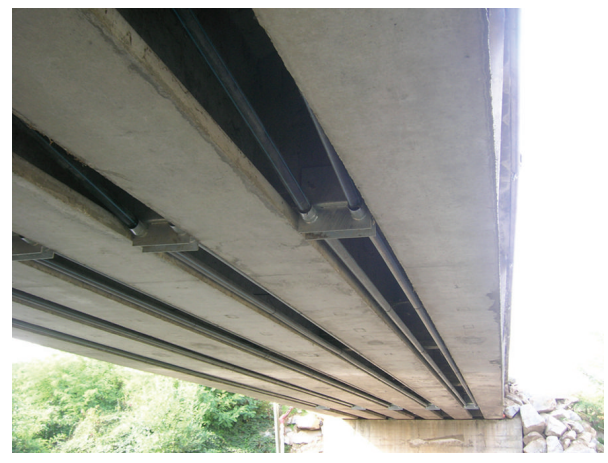

(a)

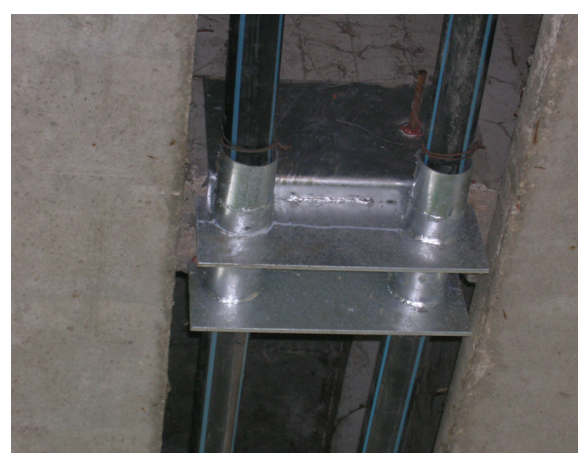

(b)

Figure 5: (a) View of external prestressing; (b) metallic saddle of deviation.

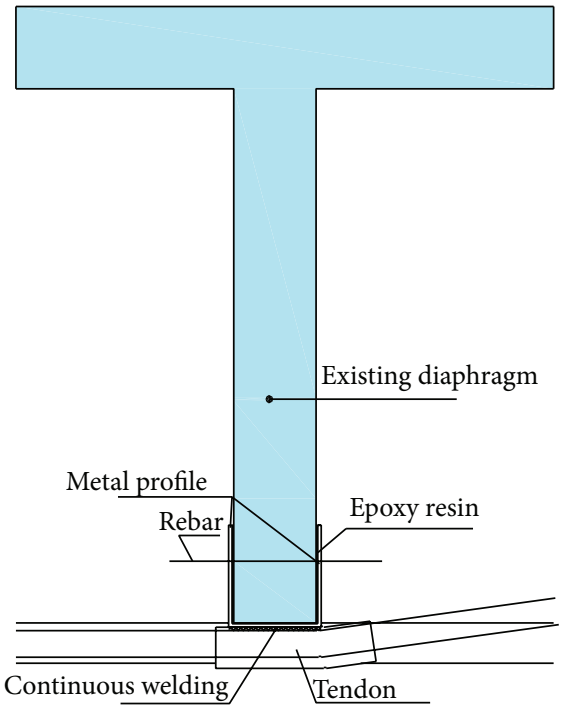

(a)

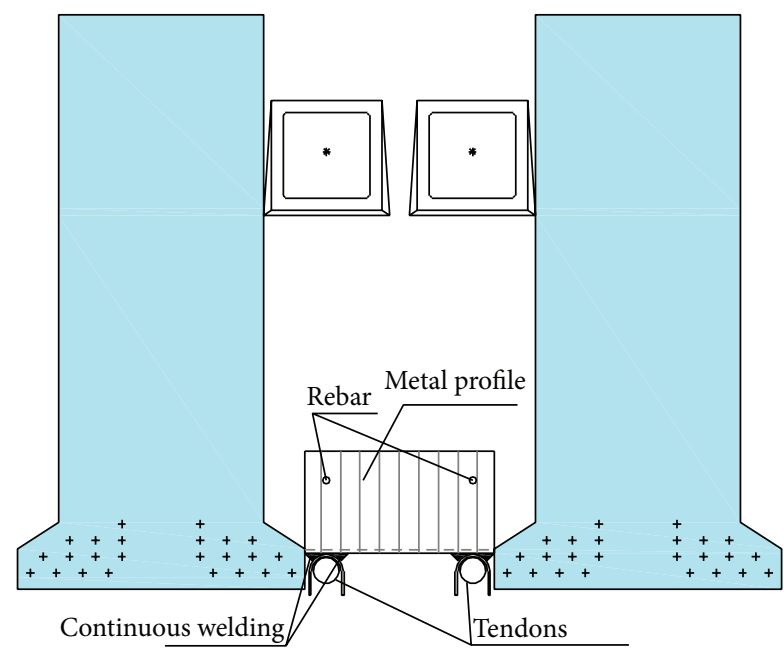

(b)

FIGURE 6: Details of connection between existing bridge and metallic saddle of deviation.

of each beam. At this aim, several numerical analyses were carried out to obtain precious information about the tension and strain fields at different load stages.

First, a linear-elastic calculation was performed to know the force that the deck was expected to undertake at service limit state (SLS) and the stress distribution along the height of the beam cross-section.

Second, a simple sectional model was used to calculate the capacity of strengthened beam at ULS. It allowed considering just the principal geometrical and mechanical parameters, providing an easy control of results. Finally, a NLFEA was performed at ULS using the software VecTor2 [21], which implements the MCFT, originally proposed by Vecchio and Collins [14], and its upgrading [15].

3.2. Beam Setup. As described in Scheme of Rehabilitation Proposed section, the reinforcement of primary beams was carried out with a new system of unbonded prestressing, disposed externally to the cross-section of beam (Figure 7).

Two groups of bonded strands were originally used for the $\mathrm{RC}$ beam. The first was characterized by strands with straight axis along the beam; the second group was placed with a variable slope of strands, as shown in Figure 6(a). Each strand was $0.5^{\prime \prime}$ in equivalent diameter, while the yield and ultimate strength of steel were $f_{p(1) k}=1575 \mathrm{MPa}$ and $f_{t}=1750 \mathrm{MPa}$, respectively.

The slab on the beams had a thickness of $200 \mathrm{~mm}$ and rebar along two orthogonal directions in its plane was used. Along the longitudinal direction, the flexural reinforcement was provided by $2 \phi 8 \mathrm{~mm}+1 \phi 12 \mathrm{~mm}$ on the top (for the bending moment close to support) and $4 \phi 8 \mathrm{~mm}$ on the bottom (for the bending moment at half span) for each width of slab pertaining to considered beam $(=1160 \mathrm{~mm})$. In the transversal direction $5 \phi 12 \mathrm{~mm} / \mathrm{m}$ was used both on the top and on the bottom of slab. 


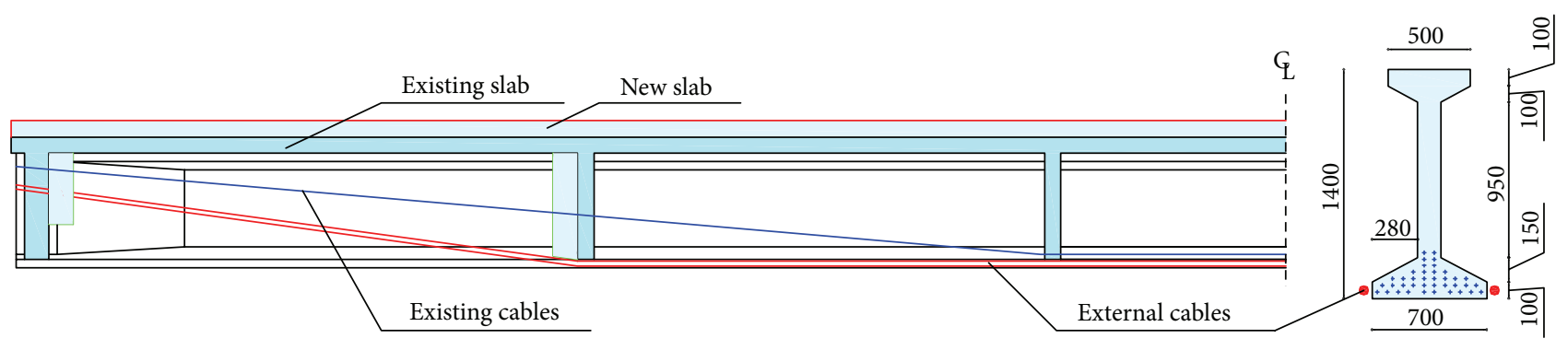

(a)

(b)

FIGURE 7: (a) Longitudinal and (b) transversal rehabilitation scheme of beam.

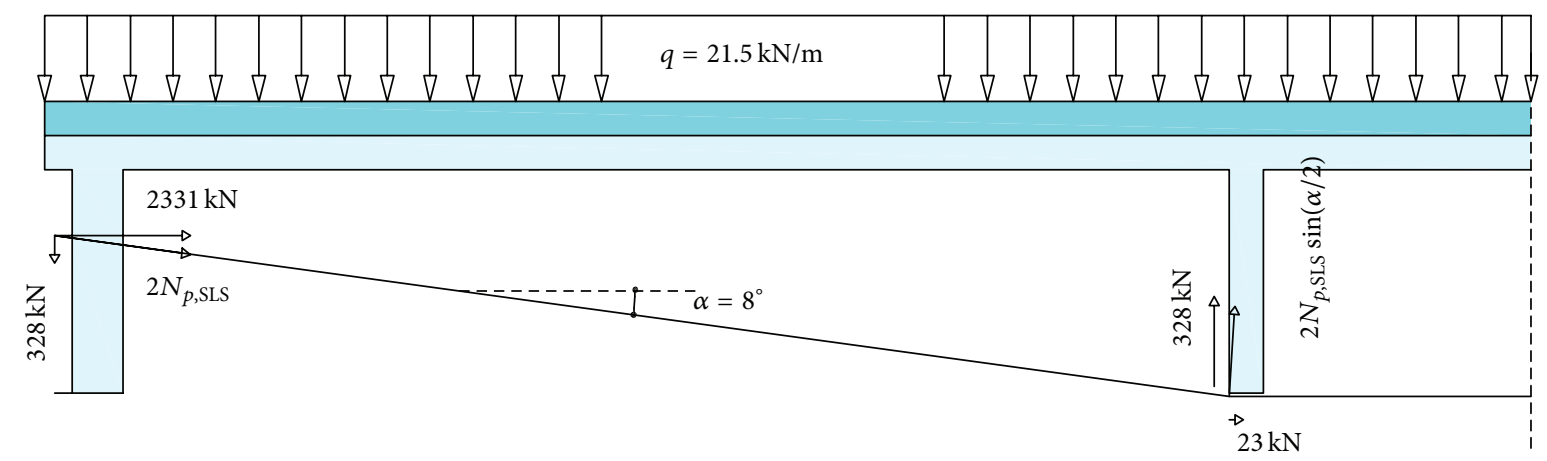

FIGURE 8: Concentrated forces equivalent to external prestressing actions at support and deviation of external cable sections.

The shear reinforcement was variable along the beam. Stirrups with two legs $\phi 8 \mathrm{~mm}$ and $\phi 10 \mathrm{~mm}$, spacing $250 \mathrm{~mm}$, were used for the region between the support and $5.25 \mathrm{~m}$, $\phi 8 \mathrm{~mm}$, spacing $250 \mathrm{~mm}$, for the region between $5.25 \mathrm{~m}$ and $10.25 \mathrm{~m}$, and $\phi 8 \mathrm{~mm}$ and $\phi 6 \mathrm{~mm}$, spacing $250 \mathrm{~mm}$, for the region between $10.25 \mathrm{~m}$ and $15.25 \mathrm{~m}$. The beam was of length $30.5 \mathrm{~m}$ and it is symmetrically loaded and reinforced.

As previously mentioned, the concrete for the beam is characterized by a cylindrical strength $f_{\mathrm{cm}}=35 \mathrm{MPa}$, while the concrete for the existing top slab has a cylindrical strength $f_{\mathrm{cm}}=20 \mathrm{MPa}$.

For the rehabilitation of bridge, the primary beams have been retrofitted with a new deck of $250 \mathrm{~mm}$ thickness $\left(f_{\mathrm{cm}}=\right.$ $35 \mathrm{MPa}$ ), which was linked to the existing slab by steel connectors and a system of two external prestressing cables $8 / 06^{\prime \prime}$ strands for each beam. The axial force for each external prestressing cable at SLS was $N_{p, S L S}=1177 \mathrm{kN}$; thus the equivalent balances vertical load was equal to $21.5 \mathrm{kN} / \mathrm{m}$ (Figure 8).

3.3. Linear-Elastic Analysis at SLS. The reinforcement of the beam by the external tendons system has modified the stress regime of the structural element. These modifications were allowed to carry the new loads.

The structure, after the reinforcement, is composed by two parts of concrete casted in different times. If, as a result of the external loads and the prestressing, the beam remains fully compressed (or with tensile tension values less than elastic limit), then it is possible to apply the principle of superposition. Therefore, total forces are due by sum of prestressing and external load. This assumption is no longer valid when concrete is cracked (i.e., at failure).

Three steps with different effects were taken into account: (1) dead load, prestressing, and prestress losses; (2) dead load due to the just casted new deck; and (3) the cross-section of the beam composed by the new deck also.

The effects in the three different stages were evaluated separately and then subsequently summed.

In Figure 9 the stress shape along the depth for a crosssection at the midspan of the beam is shown. The beam is subjected to compression stress only.

3.4. Sectional Analysis at ULS. Several simple models were developed by the same authors to handily evaluate the shear strength of RC and fibrous reinforced concrete (FRC) beams [22-27]. However, the expected failure mode of beam taken into account allows obtaining the ultimate load by a sectional calculation.

The external forces to apply at the beam to take into account the actions of external prestressing cables are evaluated by simple geometric considerations, as shown in Figure 8 . 


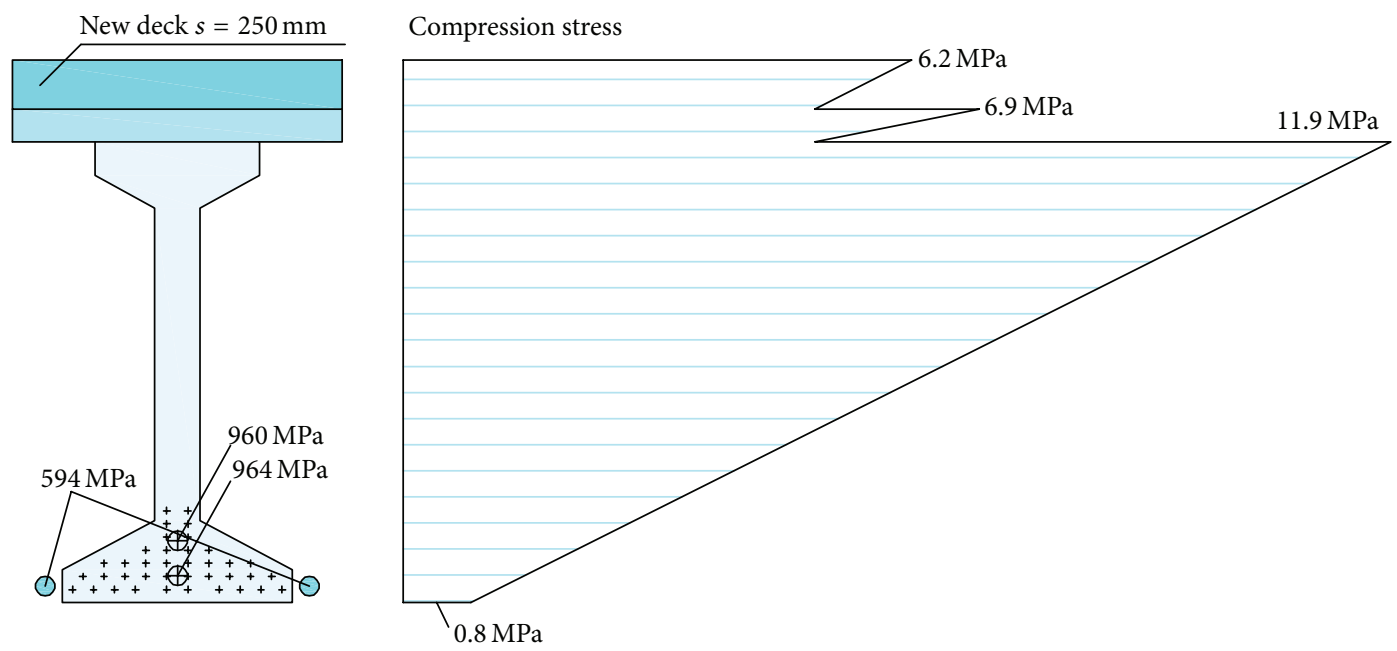

FIGURE 9: Stress diagram at midspan cross-section of beam.

Figure 10 showed the free-body midspan cross-section of beam, where $x_{c}$ is the distance between the top compressed part of beam and the neutral axis; $A_{p 1}=24 \times 93=$ $2232 \mathrm{~mm}^{2}$ and $A_{p 2}=14 \times 93=1302 \mathrm{~mm}^{2}$ are the area of equivalent inclined and straight cable, respectively; and $N_{p, \text { SLS }}=1177 \mathrm{kN}$ is the axial force for each external prestressed cable.

Assuming the stress-block distribution for compressed concrete, the equilibrium along the longitudinal axis of beam allows obtaining the position of neutral axis:

$$
0.8 x_{c} f_{\mathrm{cm}} B=A_{p 1} f_{p(1) k}+A_{p 2} f_{p(1) k}+2 N_{p, \mathrm{SLS}} \cos \alpha .
$$

The distance between the top compressed part of beam and the neutral axis is $242 \mathrm{~mm}$. The bending equilibrium equation allows obtaining the flexural strength of beam

$$
\begin{aligned}
M_{u}= & -\frac{0.8 x_{c}}{2} 0.8 x_{c} f_{\mathrm{cm}} B+d_{a} 2 N_{p, \mathrm{SLS}} \cos \alpha \\
& +d_{b} A_{p 2} f_{p(1) k}+d_{c} A_{p 1} f_{p(1) k},
\end{aligned}
$$

obtaining $M_{u}=13013 \mathrm{kNm}$.

Having known the flexural strength of beam, the load bearing of beam is evaluable writing a simple equation of equilibrium between the external forces and the reaction of support. The equivalent force of external distributed load is applied at a distance from the support equal to $L / 4=7.63 \mathrm{~m}$, while the actions due to the external prestressing cables are represented by concentrated forces applied in the pole $A$ and at distance $L_{p}=6.40 \mathrm{~m}$ from the support (Figure 8).

3.5. The Modified Compression Field Theory (MCFT). Several analytical formulations have been suggested to reproduce the response of RC structural elements subject to different load conditions, adopting models based on several constitutive laws and mechanical theories [14, 28, 29].

Between these, the MCFT represents a general model for the load-deformation behaviour of two-dimensional cracked reinforced concrete subjected to shear and flexure. It models concrete considering concrete stresses in the principal directions summed with reinforcing stresses assumed to be only axial. The concrete stress-strain behaviour in compression and tension was derived originally from tests performed by Vecchio and Collins [30].

3.6. Nonlinear Analyses at ULS. Figure 11 shows the mesh generated for the beam taken into account. Thanks to the complete symmetry, only half beam was modelled and suitably restrained to the symmetrical axis.

The mesh was composed of four-node triangular and rectangular elements with variable thickness to represent the concrete and two-node truss bars with uniform crosssectional area for rebar and bonded cables. The colours indicate areas with different reinforcement percentage. The finite element size was chosen adopting the cover as vertical size and a ratio between sides of rectangular element close to one. The action induced by external prestressed cables was modelled as concentrate nodal forces on steel plates with a uniform thickness and fully connected to concrete, providing regions without rotations (Figure 12).

Perfect steel-to-concrete bond has been assumed for both rebars and inclined and straight cables. For the latter, a prestrain has been considered to take into account the prestressing action. It was determinate considering a Young modulus for the steel of cables equal to $186 \mathrm{GPa}$ and an axial force at SLS for each tendon equal to about $1000 \mathrm{MPa}$ (including the force degradation due to shrinkage and creep); thus a prestrain equal to $5.6 \mathrm{~mm} / \mathrm{m}$ has been used.

The software VecTor2 allows managing many parameters concerning mechanical characteristics of materials and those constitutive laws. The numerical analyses were carried out assuming the default values for each parameter and specifically taking the Hognestad parabola for concrete, an elasticplastic law for steel rebars, and, finally, the known RambergOsgood formulation for prestressing steel [21]. 

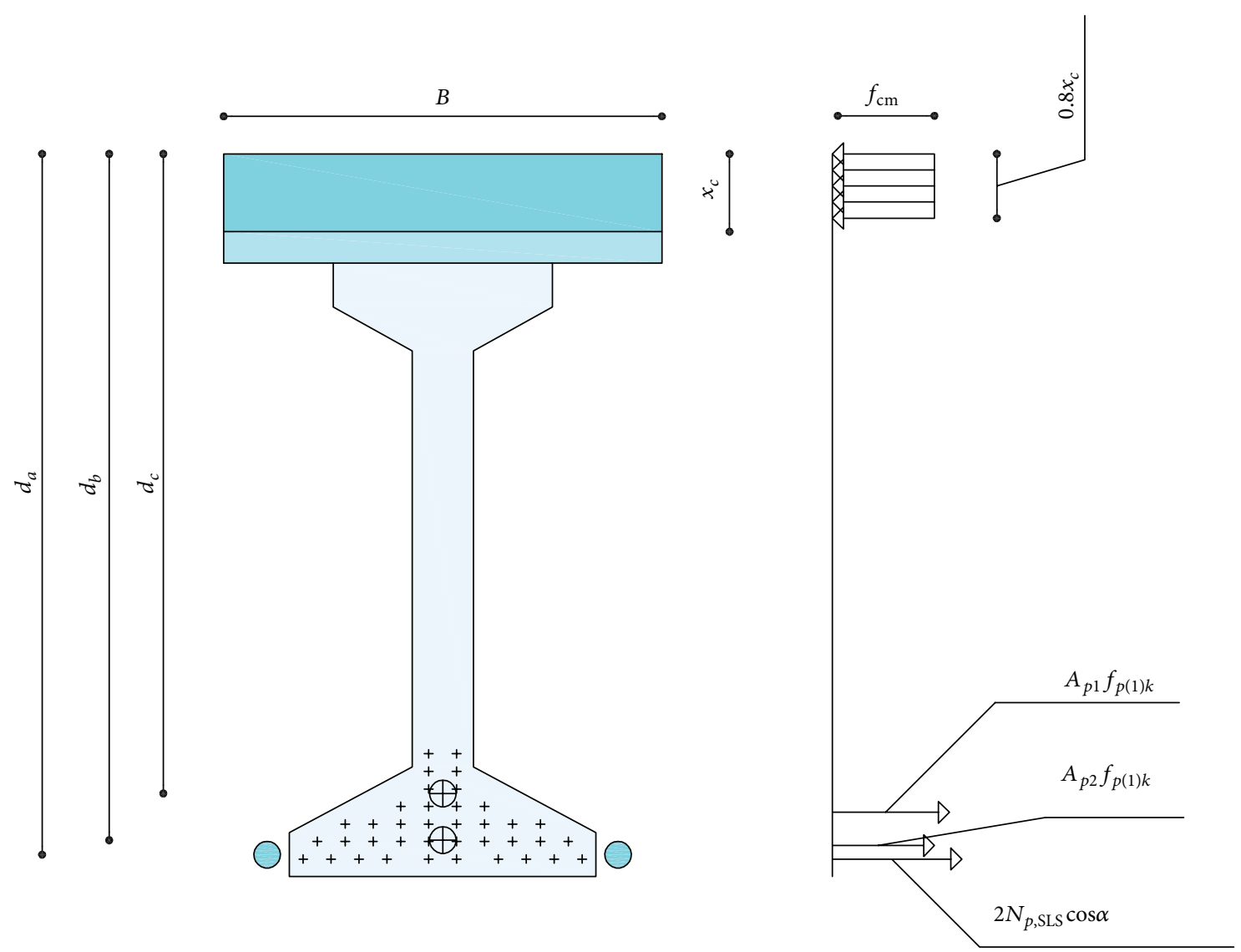

FIGURE 10: Free-body forces diagram at midspan cross-section of beam.

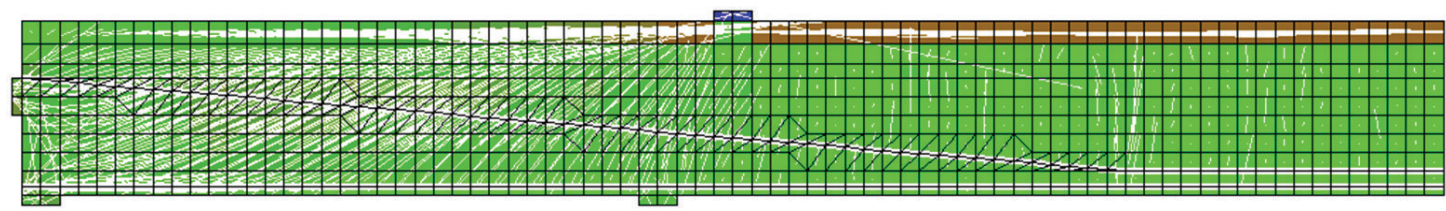

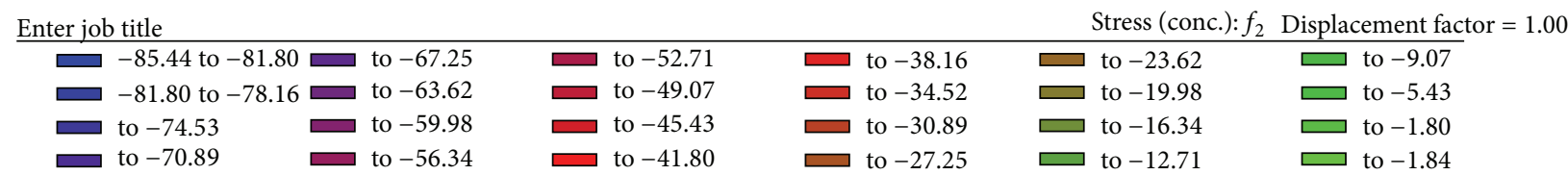

FIGURE 11: Finite element model of half beam.

NLFEAs were performed assigning three different load cases: the statical self-weight on all concrete elements, the statically external prestressing forces, and the monotonically increasing displacement on the node located in the middle of the top steel transfer plate, placed at $L / 4$ from the support. The total load has been computed as twice the reaction force at the support. Thus, the displacement controlled procedures have been able to reproduce the postpeak branch of the loaddisplacement curve.
Figure 13 illustrates the load-displacement numerical curve evaluated in the midspan cross-section of beam. The load capacity at ULS provided by the NLFEA is equal to $1883 \mathrm{kN}$, value close to that obtained by sectional analysis. The large postpeak branch shows a flexural failure with a constant increment of strength and a wide deflection at midspan crosssection of beam has been obtained.

The NLFEA provided also interesting information about the crack pattern and stress fields at ULS (Figure 14). 

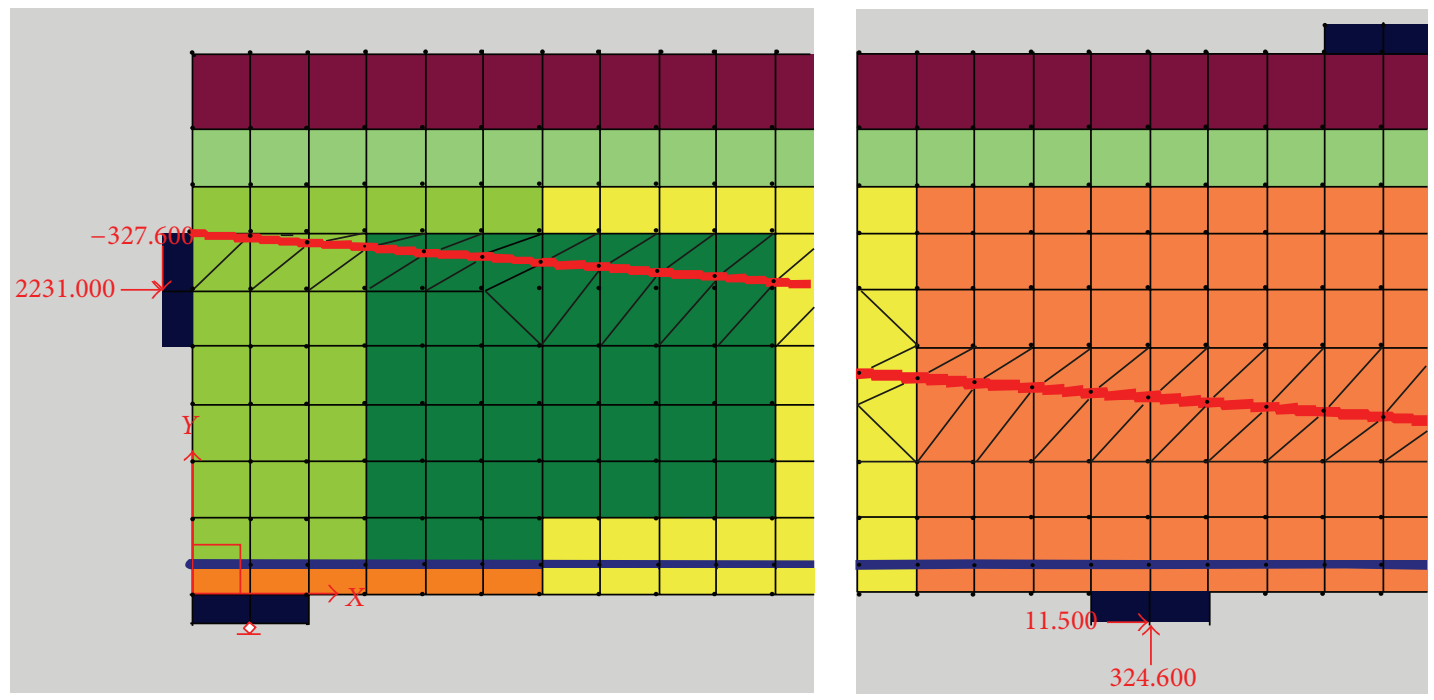

FIGURE 12: Concentrate nodal forces on steel plates due to external prestressing cables.

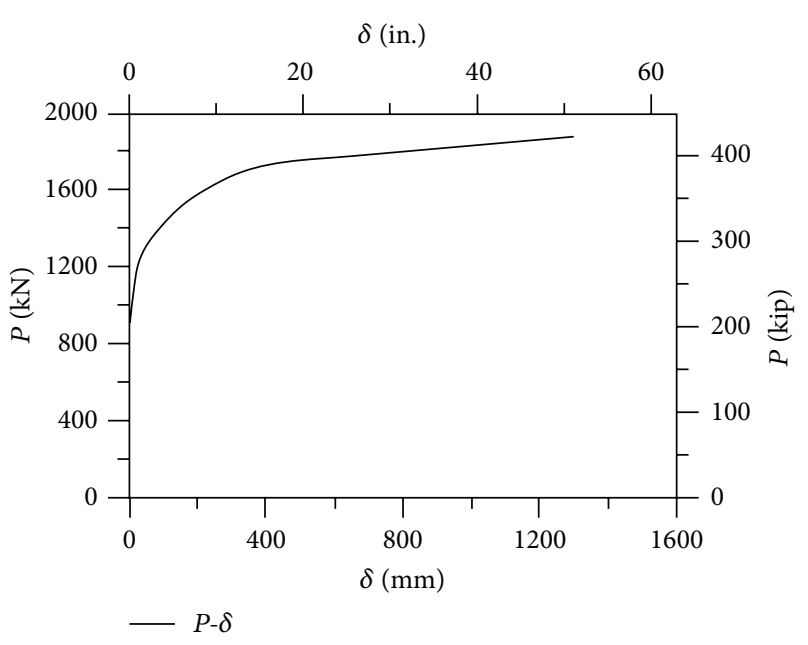

FIGURE 13: Load-displacement numerical curve.

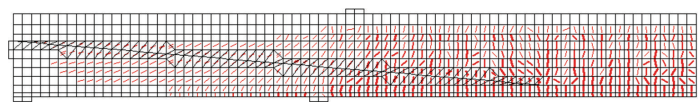

FIGURE 14: Crack pattern of beam at failure.

The crack pattern at ULS confirmed the flexural crisis of structural member, with large vertical cracks in the midspan of beam. In the shear span region, cracks are inclined with respect to the longitudinal axis and slightly wider.

The stress fields of concrete are clearly compatible with the crack pattern described above; thus the compression stress level at beam crisis is less than cylindrical strength of concrete and when the bonded cables strain reaches the maximum value available, then beam fails.

\section{Conclusions}

An application of external prestressing retrofitting has been presented. The structure element analyzed was an existing single span bridge for which it was necessary to improve the load capacity, allowing the transit of larger loads as trains.

An in situ campaign of tests has allowed an accurate design with optimized choices, which have been described.

The design of retrofitting for the considered case of study, the Terdoppio bridge, was investigated by several numerical analyses which have provided precious information about the load capacity and stress and strain fields at different load stages.

The linear-elastic analysis provided information about the stress shape along the cross-section of the beam, confirming that the beam was subjected to compression only.

The sectional model has allowed calculating the flexural capacity of strengthened beam, considering few parameters to obtain accurate values of strength and an easy control of results.

In addition, the sophisticated FEM software VecTor2, which implements the well-known MCFT, has been used to perform different NLFEAs. Numerical results have been reported and discussed, showing the ability of the theoretical model adopted to provide a response of the beam analyzed subjected to transversal load in agreement with the values obtained by the sectional method.

Furthermore, interesting information has been provided by the NLFEAs about the crack pattern and stress fields of structural member considered at each stage of load, predicting a large ductile branch at failure as expected in design phase.

\section{Conflict of Interests}

The authors declare that there is no conflict of interests regarding the publication of this paper. 


\section{References}

[1] A. F. Daly and W. Witarnawan, "Strengthening of bridge using external post-tensioning," in Proceedings of the Conference of Eastern Asia Society for Transportation (EASTS '97), Seoul, Republic of Korea, October 1997.

[2] A. Daly and W. Witarnawan, "A method for increasing the capacity of short and medium span bridges," in Proceedings of the 10th REAAA Conference, Tokyo, Japan, September 2000.

[3] F. Seible, "Advanced composites materials for bridges in the 21st century," in Proceedings of the 2nd International Conference on Advanced Composite Materials in Bridges and Structures (ACMBS '96), pp. 17-30, Montreal, Canada, 1996.

[4] J. M. Stallings, J. W. Tedesco, M. El-Mihilmy, and M. McCauley, "Field performance of FRP bridge repairs," Journal of Bridge Engineering, vol. 5, no. 2, pp. 107-113, 2000.

[5] T. Hassan and S. Rizkalla, "Flexural strengthening of prestressed bridge slabs with FRP systems," PCI Journal, vol. 47, no. 1, pp. 76-93, 2002.

[6] P. Casadei, N. Galati, G. Boschetto, K. Y. Tan, A. Nanni, and G. Galecki, "Strengthening of impacted prestressed concrete bridge I-girder using prestressed near surface mounted C-FRP bars," in Proceedings of the 2nd International Congress Fédération Internationale du Béton, Naples, Italy, June 2006.

[7] G. Campione, P. Colajanni, L. La Mendola, and N. Spinella, "Ductility of reinforced concrete members externally wrapped with fiber-reinforced polymer sheets," Journal of Composites for Construction, vol. 11, no. 3, pp. 279-290, 2007.

[8] P. Colajanni, F. de Domenico, N. Maugeri, A. Recupero, N. Spinella, and G. Mantegazza, "Experimental results of RC columns strengthened with fibre reinforced cementitious mortars," in Proceedings of 3 rd International Conference on Concrete Repair, Rehabilitation and Retrofitting (ICCRRR '12), P. Moyo, Ed., pp. 1137-1143, CRC Press, Cape Town, South Africa, 2012.

[9] P. Colajanni, F. De Domenico, A. Recupero, and N. Spinella, "Concrete columns confined with fibre reinforced cementitious mortars: experimentation and modelling," Construction and Building Materials, vol. 52, pp. 375-384, 2014.

[10] P. Colajanni, M. Papia, and N. Spinella, "Stress-strain law for confined concrete with hardening or softening behavior," Advances in Civil Engineering, vol. 2013, Article ID 804904, 11 pages, 2013.

[11] M. H. Harajli, "Strengthening of concrete beams by external prestressing," PCI Journal, vol. 38, no. 6, pp. 76-78, 1993.

[12] J. Choi, "Comparative study of effective stresses of concrete beams strengthened using carbon-fibre-reinforced polymer and external prestressing tendons," Structure and Infrastructure Engineering, vol. 10, no. 6, pp. 753-766, 2014.

[13] G. Bertagnoli, V. I. Carbone, L. Giordano, and G. Mancini, "Repair and strengthening of damaged prestressed structures," in Durability of Post-Tensioning Tendons, vol. 15 of FIB Bullettin, pp. 139-153, 2001.

[14] F. J. Vecchio and M. P. Collins, "The modified compression field theory for reinforced concrete elements subjected to shear," Journal of the American Concrete Institute, vol. 83, no. 2, pp. 219231, 1986.

[15] F. J. Vecchio, "Disturbed stress field model for reinforced concrete: formulation," ASCE Journal of Structural Engineering, vol. 126, no. 9, pp. 1070-1077, 2000.

[16] F. Minelli and F. J. Vecchio, "Compression field modeling of fiber-reinforced concrete members under shear loading," ACI Structural Journal, vol. 103, no. 2, pp. 244-252, 2006.
[17] P. Colajanni, L. la Mendola, S. Priolo, and N. Spinella, "Experimental tests and FEM model for SFRC beams under flexural and shear loads," in Proceedings of the Seismic Engineering International Conference Commemorating the 1908 Messina and Reggio Calabria Earthquake (MERCEA '08), vol. 1020, pp. 872-879, Reggio Calabria, Italy, July 2008.

[18] N. Spinella, P. Colajanni, and L. La Mendola, "Nonlinear analysis of beams reinforced in shear with stirrups and steel fibers," ACI Structural Journal, vol. 109, no. 1, pp. 53-64, 2012.

[19] Italferr, Sovraccarichi per il Calcolo dei Ponti Ferroviari-Istruzioni per la Progettazione, l'esecuzione ed il Collaudo, I/SC/PS$\mathrm{OM} / 2298-2 / 6 / 1995,1995$.

[20] A. R. Marì Bernat, A. Cladera, E. Oller, and J. M. Bairan Garcia, "Shear design of FRP reinforced concrete beams without transverse reinforcement," Composites B: Engineering, vol. 57, pp. 228-241, 2014.

[21] P. S. Wong and F. J. Vecchio, "VecTor2 and FormWorks user's manual," Tech. Rep., Department of Civil Engineering, University of Toronto, Toronto, Canada, 2002.

[22] A. Recupero, A. D’Aveni, and A. Ghersi, "Bending momentshear force interaction domains for prestressed concrete beams," ASCE Journal of Structural Engineering, vol. 131, no. 9, pp. 1413-1421, 2005.

[23] P. Colajanni, A. Recupero, and N. Spinella, "Shear strength prediction by modified plasticity theory for sfrc beams," in Seismic Engineering International Conference Commemorating the 1908 Messina and Reggio Calabria Earthquake (MERCEA '08), vol. 1020, no. 1, pp. 888-895, 2008.

[24] N. Spinella, P. Colajanni, and A. Recupero, "Simple plastic model for shear critical SFRC beams," Journal of Structural Engineering, vol. 136, no. 4, pp. 390-400, 2010.

[25] P. Colajanni, A. Recupero, and N. Spinella, "Generalization of shear truss model to the case of SFRC beams with stirrups," Computers and Concrete, vol. 9, no. 3, pp. 227-244, 2012.

[26] N. Spinella, "Shear strength of full-scale steel fibre-reinforced concrete beams without stirrups," Computers and Concrete, vol. 11, no. 5, pp. 365-382, 2013.

[27] P. Colajanni, A. Recupero, and N. Spinella, "Design procedure for prestressed concrete beams," Computers \& Concrete, vol. 13, no. 2, pp. 1-16, 2014.

[28] J. M. B. Garcia and A. R. M. Bernat, "Shear-bending-torsion interaction in structural concrete members: a nonlinear coupled sectional approach," Archives of Computational Methods in Engineering, vol. 14, no. 3, pp. 249-278, 2007.

[29] G. Bertagnoli, G. Mancini, A. Recupero, and N. Spinella, "Rotating compression field model for reinforced concrete beams under prevalent shear actions," Structural Concrete, vol. 12, no. 3, pp. 178-186, 2011.

[30] F. J. Vecchio and M. P. Collins, "Response of reinforced concrete to in plane shear and normal stress," Tech. Rep., Department of Civil Engineering, University of Toronto, Toronto, Canada, 1982. 

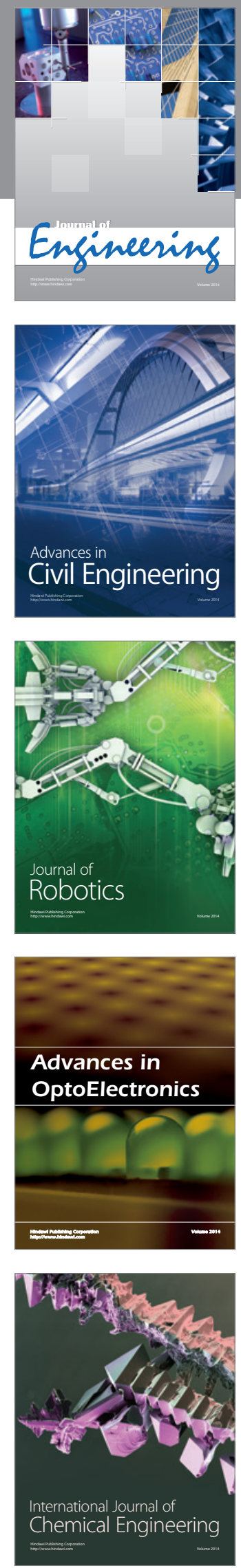

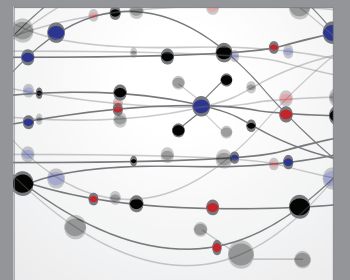

The Scientific World Journal
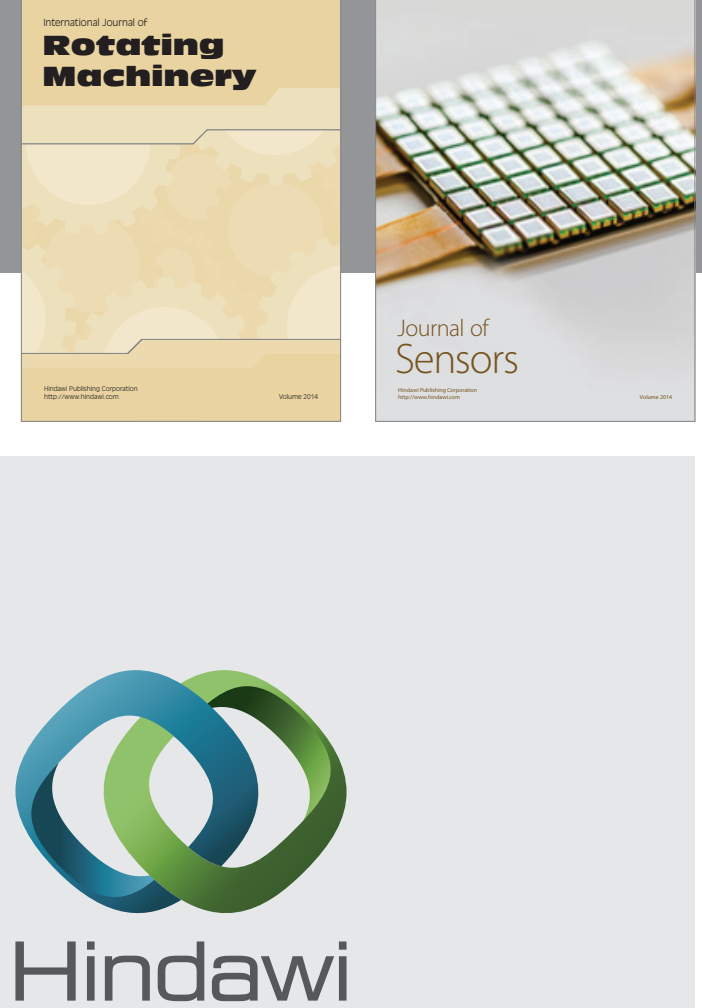

Submit your manuscripts at http://www.hindawi.com
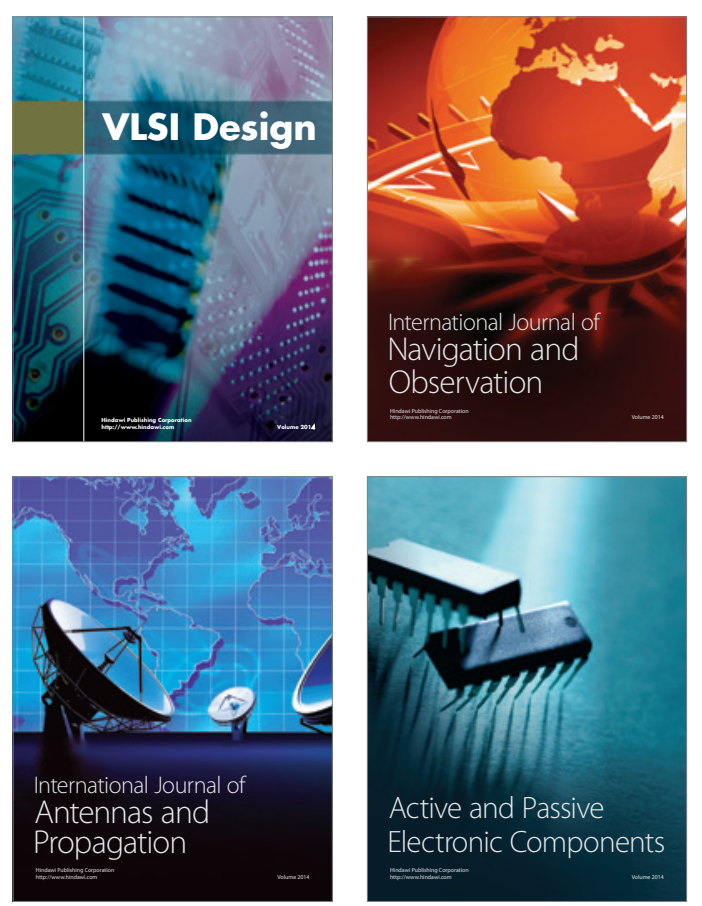
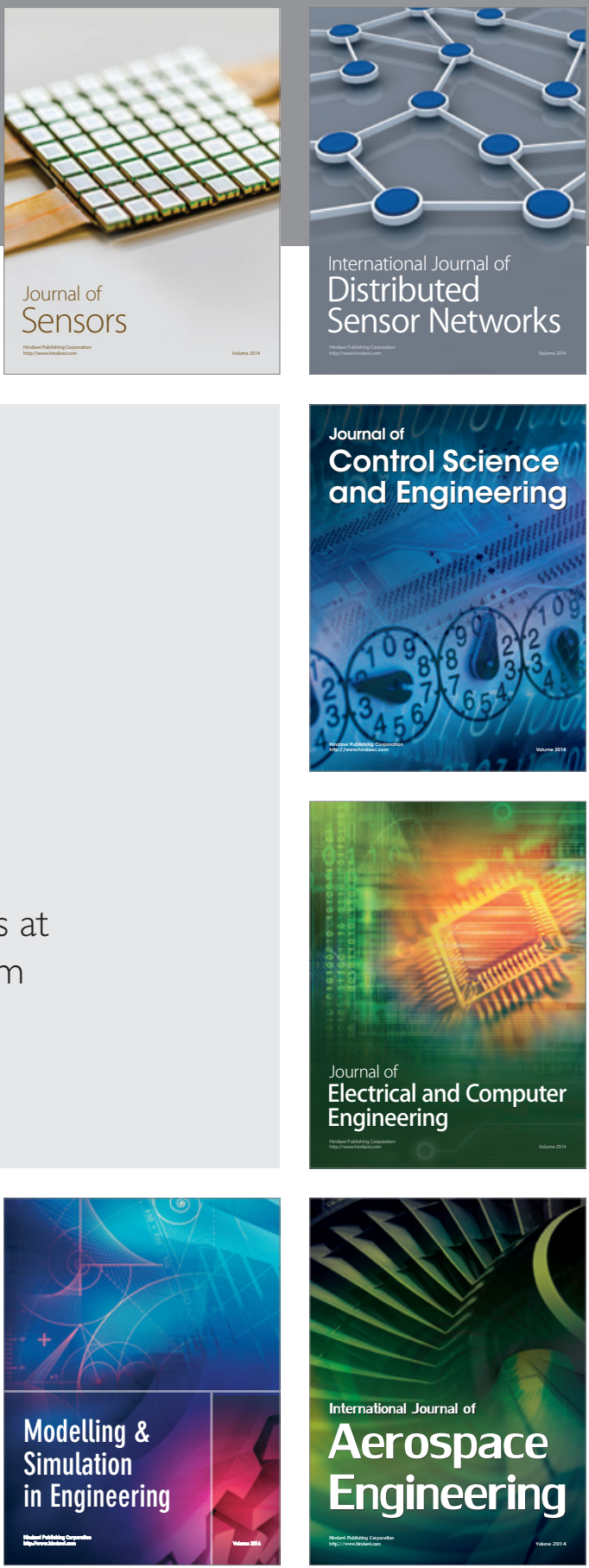

Journal of

Control Science

and Engineering
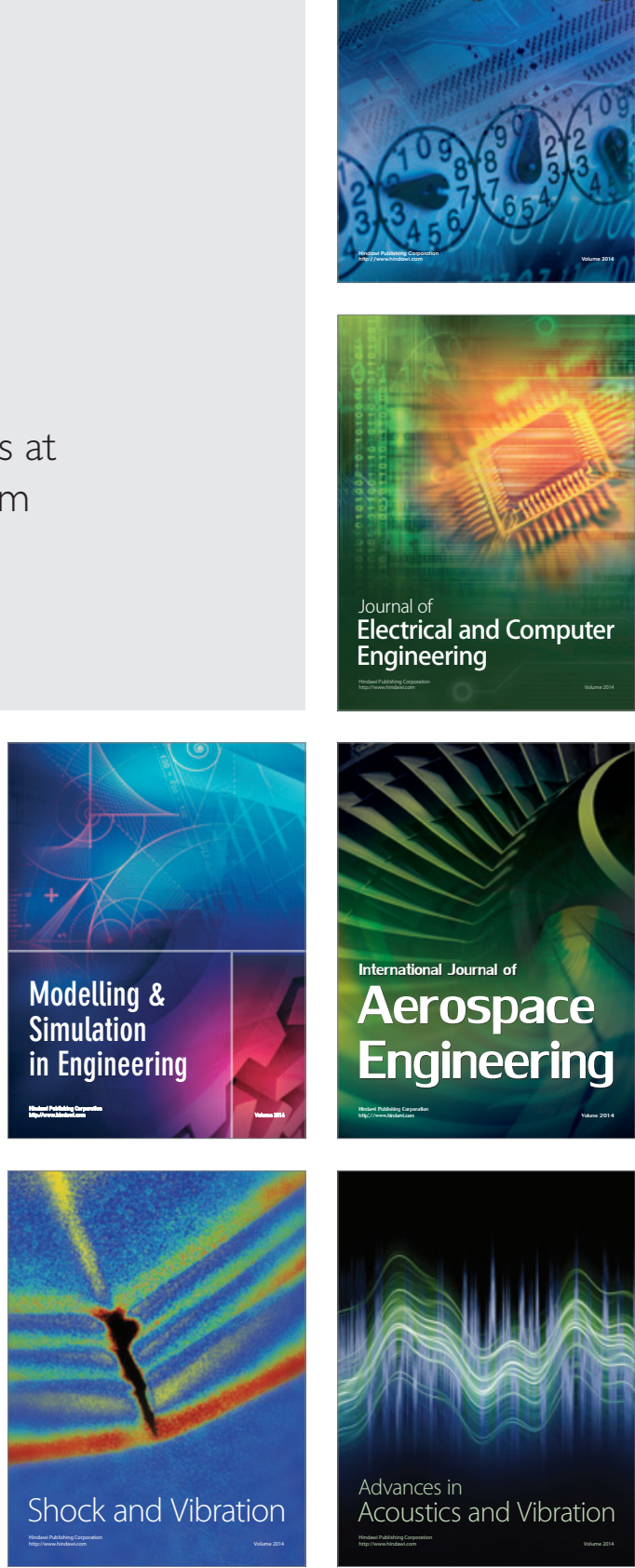